\title{
Double- Chambered Left Ventricle and Abnormal Papillary Muscle Formation
}

\author{
Yasmin Hanfi $M D^{1,2^{*}}$ and Eva Nyktari ${ }^{1}$
}

\author{
${ }^{1}$ NIHR Cardiovascular Biomedical Research Unit, Royal Brompton \\ Hospital, London, UK.
}

${ }^{2}$ Imperial College London, UK.

\section{Correspondence:}

Yasmin Hanfi, NIHR Cardiovascular Biomedical Research Unit, Royal Brompton Hospital, London, UK, E-mail: yasmin.hanfi@ gmail.com.

Received: 15 September 2018; Accepted: 21 October 2018

Citation: Yasmin Hanfi, Eva Nyktari. Double- Chambered Left Ventricle and Abnormal Papillary Muscle Formation. Cardiol Vasc Res. $2018 ; 2(4) ; 1-2$.

\section{Introduction}

Papillary muscles develop separately from mitral valve leaflet and chordae, they origin from myocardial ridge of the anterior wall and to the posterior wall of the left ventricle (LV). While chordae and mitral valve leaflets origin from a cushion tissue. The myocardial ridge gradually loosens from the ventricular wall and meanwhile the cushion tissue transforms into leaflet and chordae [1].

Abnormal papillary muscle formation may present a muscle bridge and divide the LV into two chambers. The most rare form is the superior inferior LV subdivision which our cases represent.

\section{Case Report 1}

17 years old male patient with a recent history of palpitation not related to exertion. Normal ECG findings. A transthoracic echocardiogram revealed mildly dilated left ventricle with abnormal trabeculated appearance and papillary muscle apparatus forming double chamber LV with mild obstruction. Cardiovascular magnetic resonance $(\mathrm{CMR})$ cine images showed a well formed compacted myocardial layer with normal systolic thickening excluding the LV non compaction pathology. Although confirmed an anomalous muscular bridge opposite to the normally formed anterolateral (AL) papillary muscle causing partial division of the LV in two chambers without significant obstruction at rest (Panels A, B, D). Peak recorded velocity $<1 \mathrm{~m} / \mathrm{s}$ by velocity mapping at rest (Panel E). While the posteromedial papillary muscle is abnormally hypoplastic and heavily fragmented (Panels G, H).

The mitral valve found to be with mild bellowing of its anterior leaflet with no significant regurgitation. In the late gadolinium enhancement phase the abnormally hypoplastic posteromedian papillary muscle showed limited enhancement (Panels C, F, I).
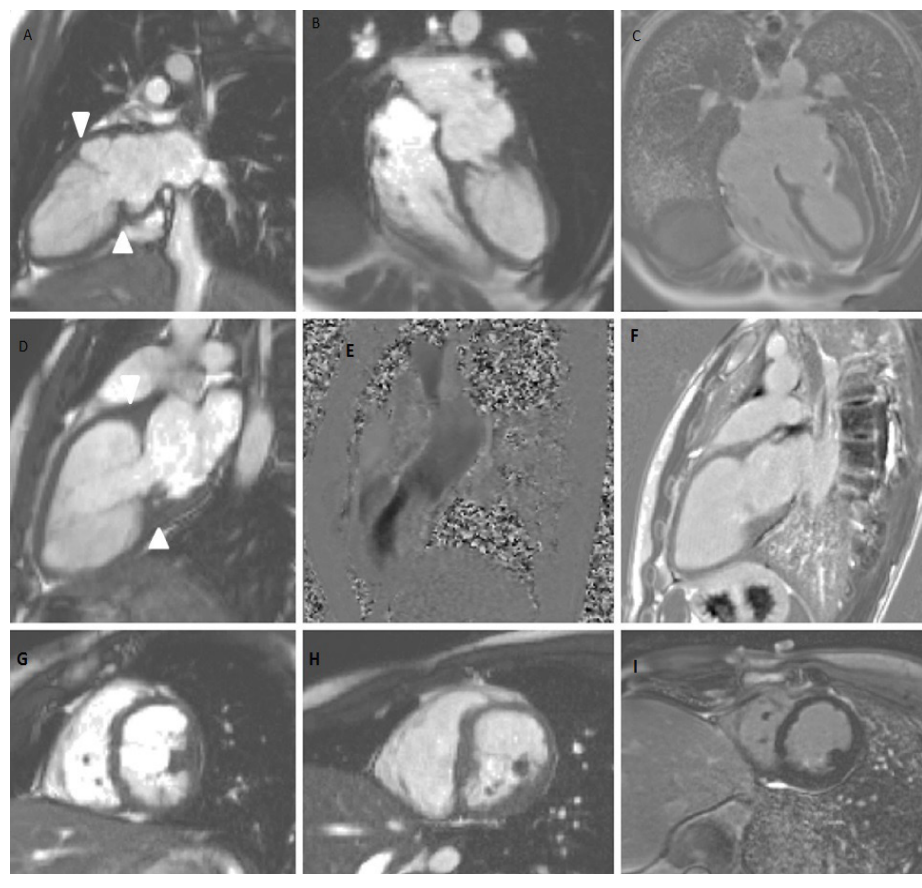

\section{Case Report 2}

A 60 year old female e referred to royal Brompton CMR department for further assessment after transthoracic echocardiography suggested an inferoapical myocardial infarction and possible hypertrophy of papillary muscle.

Cardiovascular magnetic resonance (CMR) cine images showed abnormal left ventricular with multiple coarse trabeculation (Panels 1-3) with abnormal papillary formation (Panels 4-6). No myocardial or papillary muscle late gadolinium enhancement reported. 


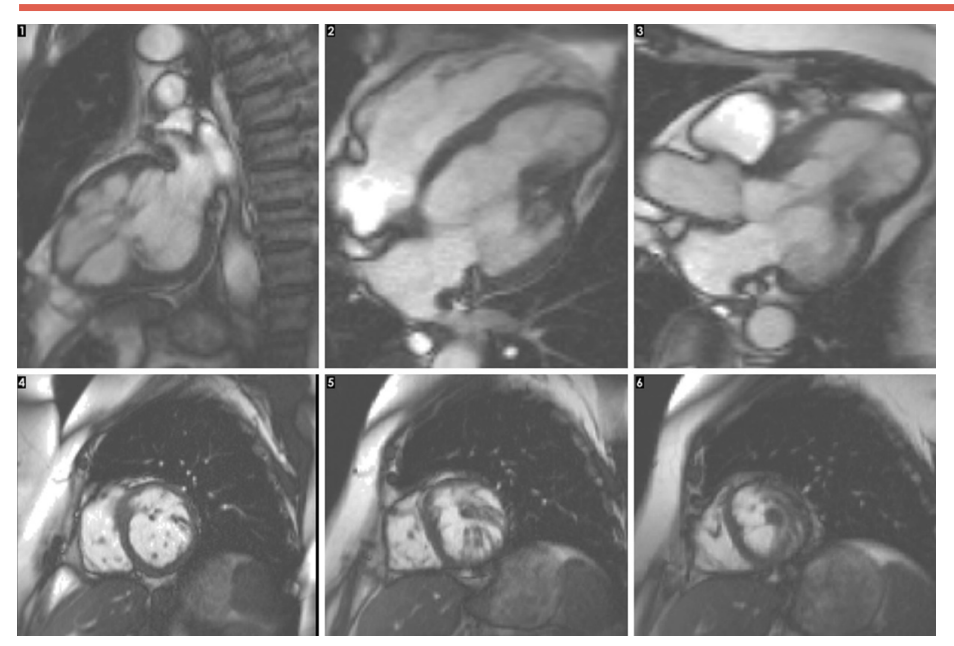

Discussion

Abnormal papillary muscle formation may present a muscle bridge and divide the LV into two chambers. Longitudinal form of subdivisions where the two chambers are parallel to each other also known as congenital LV aneurysm or double chamber LV [1-3]. It is characterized of normal contracting myocardial muscle fibre in contrast to LV aneurysm and pseudo aneurysm where infarcted, scared myocardium is the key pathology. LV diverticulum may mimic LV pseudoaneurysm, rupture of the free ventricular wall that may be contained by the adhering pericardium, organising thrombus or hematoma creating a pseudoaneurysm. True LV aneurysm is a thinned out scared myocardium with some integrity of myocardium. Myocardial infarction accounts for most LV aneurysm and pseudoaneurysm, with higher chances of inferior
MI rather than interior MI.

The transverse form of double chamber LV is the rarest associated with hypoplastic papillary muscle formation leads to a LV muscular bridge. A complete LV muscle bridge also found [4], where surgical intervention needed to correct the LV elevated pressure.

Congenital malformation of the papillary muscle also believed to affect mitral valve anomaly, when accessory bridge of fibrous tissue partially or completely divides mitral valve [5]. Or, fusion of the papillary muscle forms the parachute mitral valve.

\section{References}

1. Ohlow MA, Secknus MA, Geller JC, et al. Prevalence and outcome of congenital left ventricular aneurysms and diverticula in an adult population. Cardiology. 2009; 112: 287-293.

2. Ohlow MA, von Korn H, Lauer B, Characteristics and outcome of congenital left ventricular aneurysm and diverticulum: Analysis of 809 cases published since 1816. Int J Cardiol. 2015; 185: 34-45.

3. Nacif MS, Mello RA, Lacerda Junior OO, et al. Doublechambered left ventricle in an adult: diagnosis by CMRI. Clinics. 2010; 65: 1393-1395.

4. Kaski JP, Kilner PJ, El-Saiedi S, et al. A new variety of doublechambered left ventricle. Eur Heart J. 2010; 31: 2676.

5. Baño-Rodrigo A, Van Praagh S, Trowitzsch E, et al. Doubleorifice mitral valve: a study of 27 postmortem cases with developmental, diagnostic and surgical considerations. Am J Cardiol. 1988; 61: 152-160. 